University of Nebraska - Lincoln

DigitalCommons@University of Nebraska - Lincoln

3-2009

\title{
What Matters, and What Matters Most, for Change in Life Satisfaction in the Oldest-Old? A Study over 6 Years among Individuals $80+$
}

\author{
Anne Ingeborg Berg \\ University of Gothenburg, anne.berg@psy.gu.se \\ Lesa Hoffman \\ University of Nebraska-Lincoln, Ihoffman2@unl.edu \\ Linda Björk Hassing \\ University of Gothenburg, Linda.Hassing@psy.gu.se \\ Gerald M. McClearn \\ Pennsylvania State University, gm1@psu.edu \\ Boo Johansson \\ University of Gothenburg, Boo.Johansson@psy.gu.se
}

Follow this and additional works at: https://digitalcommons.unl.edu/psychfacpub

Part of the Psychiatry and Psychology Commons

Berg, Anne Ingeborg; Hoffman, Lesa; Hassing, Linda Björk; McClearn, Gerald M.; and Johansson, Boo, "What Matters, and What Matters Most, for Change in Life Satisfaction in the Oldest-Old? A Study over 6 Years among Individuals 80+" (2009). Faculty Publications, Department of Psychology. 419.

https://digitalcommons.unl.edu/psychfacpub/419

This Article is brought to you for free and open access by the Psychology, Department of at DigitalCommons@University of Nebraska - Lincoln. It has been accepted for inclusion in Faculty Publications, Department of Psychology by an authorized administrator of DigitalCommons@University of Nebraska - Lincoln. 
Published in Aging \& Mental Health (March 2009) 13(2): 191-201. Copyright 2009, Taylor and Francis.

ISSN 1360-7863 print/ISSN 1364-6915 online. Used by permission. doi: 10.1080/13607860802342227.

\title{
What Matters, and What Matters Most, for Change in Life Satisfaction in the Oldest-Old? A Study Over 6 Years Among Individuals 80+
}

\author{
Anne Ingeborg Berga ${ }^{a^{*}}$, Lesa Hoffman ${ }^{b}$, Linda Björk Hassing ${ }^{a}$, Gerald E. McClearn ${ }^{\mathrm{c}}$ and Boo Johansson ${ }^{\mathrm{a}}$

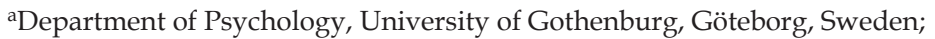 \\ ${ }^{b}$ Department of Psychology, University of Nebraska-Lincoln, Lincoln, Nebraska, US; \\ ${ }^{\mathrm{c} C e n t e r}$ for Developmental and Health Genetics, Pennsylvania State University, University Park, PA, US \\ ${ }^{*}$ Corresponding author: anne.berg@psy.gu.se
}

\begin{abstract}
Objectives: The study investigates whether markers of life satisfaction identified in a cross-sectional study quality of social network, self-rated health, depressive symptoms, locus of control and widowhood, in addition to financial satisfaction and the personality traits of extraversion and neuroticism - predict change in life satisfaction (LSI-Z) across four measurement occasions during a 6-year period in individuals aged $80+$.

Method: Data were drawn from the Swedish OCTO-Twin-study of individuals aged 80 and older.

Results: Growth curve analysis showed a relatively consistent significant linear decline in life satisfaction, but certain markers predicted change in life satisfaction. The loss of spouse, in particular in men, and higher levels of depressive symptoms were related to lower levels of life satisfaction over time.

Conclusion: The results from the study question the notion of a life-long stability of life satisfaction.
\end{abstract}

Keywords: life satisfaction; oldest-old; longitudinal; depressive symptoms; widowhood

\section{Introduction}

Satisfaction with life and contributors to well-being in very old age constitute a major concern for the elderly population as well for gerontological research. In a recent cross-sectional study we investigated the relative importance of previously identified psychosocial and health-related variables for life satisfaction in advanced age (Berg, Hassing, McClearn, \& Johansson 2006). The following set of factors emerged: quality of social network, locus of control, self-rated overall health, depressive symptoms and widowhood (Berg et al., 2006). In the present study we investigate possible changes in life satisfaction in late life and further elaborate rela tionships between life satisfaction and the identified factors within a longitudinal design. The scope of variables is also widened in the present study by the inclusion of three other variables previously found to be related to life satisfaction, namely, financial satisfaction (Revicki \& Mitchell, 1990) and the personality traits of extraversion and neuroticism (Costa \& McCrae, 1980; Headey \& Wearing, 1989; Hilleras, Jorm, Herlitz, \& Winblad, 1999).

Life satisfaction is one component of the more extensive concept of subjective well-being, and reflects, in contrast to the affective component (negative emotions and positive emotions), the way people cognitively evaluate their own lives (Diener, 1984; Diener, Suh, Lucas, \& Smith, 1999). Diener defined the concept as 'a cognitive judgmental global evaluation of one's life. It may be influenced by affect but is not itself a direct measure of emotion' (Diener, 1984). Thus, even if life satisfaction and the affectivecomponents are related (Chamberlain, 1988), they have also been found to build separate elements of subjective well-being (Lucas, Diener, \& Suh, 1996).

In the following we briefly present research findings of age-related and within-individual changes in lifesatisfaction and the predictors found to be relevant for changes in life satisfaction in old age using both subjective and objective predictors. Previous cross-sectional research has predominantly focused on therelationship between age and life-satisfaction, notaddressing potential changes in life satisfactionwithin individuals. However, in one major study of life satisfaction in the oldest-old applying multilevel models within a longitudinal design, Mroczek andSpiro (2005) found a decrease in life satisfaction in very old age on average along with large individualdifferences in linear rates of change and amount of curvature. It is important to note, however, that the use of an age-based time structure to measure changes in life satisfaction, as in the study of Mroczek and Spiro, limits the possibility of distinguishing the effects of age (i.e. crosssectional age differences) from age-related change (i.e. longitudinal age changes). Thus, although Mroczek and Spiro's study conclusions are drawn about agerelated change, this probablyreflects in part the effects of cross-sectional age differences. 
Gender differences in psychological well-being were found to be small in a recent meta-analysis (Pinquart \& Sorensen, 2001), although in subsequent cohorts men tended to report higher levels of life satisfaction than women. Thus, increasing gender differences in level of life satisfaction may be expected in younger cohorts.

The longitudinal relationship between socioeconomic status in terms of social class and income and life satisfaction has been thoroughly investigated in younger age groups but needs to be further investigated in the oldest-old. In 2000 Pinquart and Sorensen published a meta-analysis including 286 empirical studies of the influence of socioeconomic status on subjective well-being in later life (Pinquart \& Sorensen, 2000). The relationship between income and well-being was found to be relatively narrow, a finding interpreted such that the elderly adjust their needs and desires to a reduced income, keeping level of well-being unaffected. Yet a positive relationship between well-being and income has also been found (Revicki \& Mitchell, 1990) and suggests that it is rather satisfaction with financial security that matters for life satisfaction.

Widowhood is a discrete event that has shown to produce protracted decline in life satisfaction (Barer, 1994; Nagata, Yamagata, Nakamura, Miyamura, \& Asaka, 1999; Padoani et al., 1998), with great individual differences in the extent of the impact of widowhood (Lucas, Clark, Georgellis, \& Diener, 2003). Furthermore, the impact of marital transitions seems to vary between genders; bereavement contributes to a steeper decline in life satisfaction with a poorer recovery in men (Cheng \& Chan, 2006; Chipperfield \& Havens, 2001). Accordingly, future studies need to consider that, although bereavement has long-term effects on life satisfaction, people tend to differ markedly, in particular between genders, in how they are affected.

Perceived quality of social network was the marker most strongly associated with life satisfaction in our cross-sectional study (Berg et al., 2006), a relationship also found to be strong in previous research (Pinquart \& Sorensen, 2000). Number of social contacts has also been identified as a significant marker (Bowling, 1990), but qualitative measures of social network have generally been identified as more important (Berg et al., 2006; Pinquart \& Sorensen, 2000). Carstensen's Socio-emotional Selectivity Theory suggests that the awareness of limitation in future time that comes with increased age intensifies the preference of emotionally rewarding social contacts (Carstensen, 1992). Although few studies have investigated the longitudinal relationship between perceived quality of social network and life satisfaction, satisfaction with sibling contact has been found to correlate positively with level of life satisfaction four years later (McCamish-Svensson, Samuelsson, Hagberg, Svensson, \& Dehlin, 1999).

Self-rated overall health and life satisfaction has often been found to be stronger as compared with the association between objective health measures and life satisfaction in cross-sectional studies (Berg et al., 2006; Hilleras, Jorm, Herlitz, \& Winblad, 2001; Myers $\&$ Diener, 1995). In two follow-up-studies self-rated health was related to life satisfaction 2-4 years later (Bowling et al., 1996; McCamish-Svensson et al., 1999). However, Mroczek and Spiro found self-rated health to be unrelated to long term change in life satisfaction (Mroczek \& Spiro, 2005), thus, the links between health and life satisfaction over time are inconclusive.

Depressive symptoms have been associated with lower reports of life satisfaction in old age (Demura \& Sato, 2003; Fiske, Gatz, \& Pedersen, 2003). In a followup-study, level of depressive symptoms at baseline correlated highly with life satisfaction 3 years later in women (Chou \& Chi, 1999). Cross-sectional findings of increased depressive symptoms with age (Kessler, Foster, Webster, \& House, 1992; Roberts, Kaplan, Shema, \& Strawbridge, 1997) have predominantly not been observed in longitudinal studies (Dent et al., 1999; Haynie, Berg, Johansson, Gatz, \& Zarit, 2001), even though an increase was identified in a 6-year follow-up study (Wallace \& O'Hara, 1992). Taken together, depressive symptoms appear to be related to life satisfaction, but the pattern of associations and the direction over time is still uncertain.

Locus of control is another factor associated with life satisfaction in late life (Hickson, Housley, \& Boyle, 1988; Landau \& Litwin, 2001). To our knowledge, locus of control has not been investigated longitudinally as a predictor of life satisfaction. However, the opposite relationship has been stated: mental wellbeing was found to be related to greater sense of control (Wolinsky, Wyrwich, Babu, Kroenke, \& Tierney, 2003), a concept that reflects Rotter's internal-external approach (Rotter, 1966). A more definite indication of the direction of a possible direction and relationship requires additional empirical evidence.

The personality traits extraversion (extraversionintroversion) and neuroticism (neuroticism-emotionally stable) has repeatedly been identified as strongly related to life satisfaction even in old age (Costa \& McCrae, 1980; Headey \& Wearing, 1989; Hilleras et al., 2001). Basically, the extraversion trait reflects to what degree an individual is sociable and outgoing; those higher in extraversion have shown higher levels of life satisfaction, whereas neuroticism reflects degree of anxiety; those higher in neuroticism have shown lower levels of life satisfaction (Costa \& McCrae, 1980; Hilleras et al., 1999). 
Two limitations characterize the studies referred to above. First, most studies include samples younger than 80 years. Because of the deteriorations in physical and psychological health at the age of 80 , the generalization of findings of life satisfaction from samples of young-old and old-old to the oldest-old may be inappropriate. Second, an issue of major interest in the study of psychological development across the life span is the variety in pattern and degree of changes. So far, few studies have applied statistical methods that enable a thorough examination of individual differences in magnitude of change and predictors thereof. Multilevel analysis is one method that allows the consideration of inter-individual differences in intraindividual changes, which may provide results that could deepen the knowledge of life satisfaction in late life.

The aim of the present study is to investigate both the unique contribution and the relative importance of a comprehensive set of variables for changes in life satisfaction among individuals in late life using data from a longitudinal study at four measurement points over a 6-year interval. Changes in population mean and differences in intra-individual changes will be analyzed in relation to initial age, gender, widowhood, social class and financial satisfaction, perceived quality of social network, self-rated overall health, depressive symptoms, locus of control, and the personality traits of extraversion and neuroticism. In addition, the within-person effects of changes in the time-varying predictors of widowhood, financial satisfaction, perceived quality of social network, selfrated health, depressive symptoms, and locus of control will be also examined.

\section{Method: Sample}

The sample was drawn from the population-based longitudinal study, 'Origins of Variance in the OldOld,' or OCTO-Twin Study (McClearn et al., 1997). Participants were pair of twins aged 80 and older living in Sweden. As shown in Table 1, of the original sample of 702, only 453 completed the Life Satisfaction Index- $Z$ at the first measurement point. The procedure of leaving the inventory with the participant to complete and mail resulted in a selected overall healthier group of the oldest-old (see below). The exclusion of individuals with a dementia diagnosis further reduced the sample to 412. Across the three subsequent waves the sample sizes of participants completing the inventory were: wave 2, 286; wave 3,212 ; and wave 4,121 . In order to detect a possible selection bias because of twinship per se (i.e. twins differ from nontwins), in the current sample, singletons and twins were compared and found not to differ in education, social class, marital status, housing, health status or biobehavioral functions such as cognitive function or well-being. (Simmons et al., 1997).

An attrition analysis of the selected sample and the excluded participants at wave 1 showed that the selected sample was younger, $t(700)=-5.032, p<0.001$ and reported better self-rated overall health, $t(664)=$ 2.146, $p<0.05$, lower instrumental Activities of Daily Living (ADL) impairment, $t(581)=10.449, p<0.001$, and lower personal ADL impairment, $t(626)=8.120, p$ $<0.001$, performed better on the MMSE, $t(687)=14.966$, $p<0.001$, had more social contacts, $t(616)=3.089, p<$ 0.05 , and was more satisfied with the social network, $t(614)=6.667, p<0.001$. In sum, the sample represents an overall well-functioning and healthy group of nondemented individuals aged 80 and older.

Table 1. Descriptive characteristics of the sample at waves 1-4.

\begin{tabular}{|c|c|c|c|c|c|c|c|c|}
\hline & \multicolumn{2}{|c|}{$\begin{array}{c}\text { Wave } 1 \\
1991\end{array}$} & \multicolumn{2}{|c|}{$\begin{array}{c}\text { Wave } 2 \\
1993\end{array}$} & \multicolumn{2}{|c|}{$\begin{array}{c}\text { Wave } 3 \\
1995\end{array}$} & \multicolumn{2}{|c|}{$\begin{array}{c}\text { Wave } 4 \\
1997\end{array}$} \\
\hline & $M$ & $\mathrm{SD}$ & $M$ & $\mathrm{SD}$ & $M$ & $\mathrm{SD}$ & $M$ & $\mathrm{SD}$ \\
\hline Life Satisfaction Index-Z & 47.1 & 8.0 & 46.4 & 7.6 & 46.4 & 7.5 & 46.6 & 7.3 \\
\hline Age & 83.0 & 2.9 & 84.6 & 2.2 & 86.5 & 2.2 & 88.3 & 2.0 \\
\hline Years of education ${ }^{a}$ & 7.1 & 2.1 & 7.1 & 2.0 & 7.0 & 1.9 & 7.0 & 2.1 \\
\hline Financial satisfaction & 8.4 & 1.2 & 8.2 & 1.4 & 8.2 & 1.4 & 8.1 & 1.4 \\
\hline Sex & \multicolumn{2}{|c|}{ Men: $37.1 \%$} & \multicolumn{2}{|c|}{ Men: $39.2 \%$} & \multicolumn{2}{|c|}{ Men: $37.1 \%$} & \multicolumn{2}{|c|}{ Men: $31.4 \%$} \\
\hline Widowed & \multicolumn{2}{|c|}{$50.1 \%$} & \multicolumn{2}{|c|}{$53.8 \%$} & \multicolumn{2}{|c|}{$59.6 \%$} & \multicolumn{2}{|c|}{$67.8 \%$} \\
\hline Upper class & \multirow{2}{*}{\multicolumn{2}{|c|}{$13.7 \%$}} & \multicolumn{2}{|c|}{$14.6 \%$} & \multicolumn{2}{|c|}{$14.1 \%$} & \multicolumn{2}{|c|}{$15.7 \%$} \\
\hline Middle class & & & \multicolumn{2}{|c|}{$41.9 \%$} & \multicolumn{2}{|c|}{$43.7 \%$} & \multicolumn{2}{|c|}{$47.1 \%$} \\
\hline Lower class & \multicolumn{2}{|c|}{$\begin{array}{l}38.6 \% \\
47.7 \%\end{array}$} & \multicolumn{2}{|c|}{$43.5 \%$} & \multicolumn{2}{|c|}{$42.3 \%$} & \multicolumn{2}{|c|}{$37.2 \%$} \\
\hline Self-rated overall health & 9.1 & 1.8 & 9.1 & 1.6 & 9.5 & 1.7 & 9.1 & 1.7 \\
\hline Depressive symptoms & 28.6 & 8.5 & 25.4 & 7.5 & 25.6 & 6.5 & 24.7 & 6.1 \\
\hline Locus of control & 37.0 & 4.1 & 36.8 & 4.0 & 36.9 & 4.6 & 36.6 & 3.7 \\
\hline Quality of social network & 9.6 & 2.4 & 9.3 & 2.3 & 9.3 & 2.2 & 9.5 & 2.0 \\
\hline Neuroticism wave 1 & 2.8 & 2.4 & 2.5 & 2.4 & 2.5 & 2.3 & 2.5 & 2.5 \\
\hline Extraversion wave 1 & 5.1 & 2.2 & 5.2 & 2.1 & 5.2 & 2.1 & 5.2 & 2.0 \\
\hline
\end{tabular}

Notes: $M=$ mean, $\mathrm{SD}=$ standard deviation.

${ }^{a}$ Corresponds to average years of education in the Swedish cohort born before 1911. 


\section{Procedure}

Trained research nurses visited the participants in their homes for the data collection every second year from 1991 to 1997. The testing sessions lasted 3-4 h including testing and rest breaks. Tests requiring concentration and vigilance were administered during the first hour. Participants were asked to complete and mail back some of the inventories (Life-Satisfaction Index-Z, Locus of Control, and Eysenck Personality Inventory, EPI) after the testing session.

\section{Measures}

Life satisfaction

The Life Satisfaction Index-Z: LSI-Z (Wood, Wylie, \& Sheafor, 1969) is a 13-item version of the original 20-item Life Satisfaction Index-A (Neugarten, Havighurst, \& Tobin, 1961) and consists of statements reflecting life satisfaction in old age such as: 'As I grow older, things seem better than I thought they would be' and 'When I think back over my life, I didn't get most of the important things I wanted'. Participants rated each statement from 'agree totally' $1 / 41$ to 'do not agree at all' $1 / 45$. Negative items were reverse-coded. The sum of the scale ranges from 13 to 65, with higher scores indicating greater life satisfaction. In cases with three or fewer than three missing items on the LSI-Z, a mean imputation was conducted. Participants completed and returned the inventory by mail. Cronbach's alpha at wave 1 was 0.78 .

\section{Predictor variables}

Gender, age, widowhood, SES, financial satisfaction, perceived quality of social network, self-rated overall health, depressive symptoms, locus of control and the personality traits extraversion and neuroticism were used to explain individual differences in level and change of life satisfaction across the four measurement occasions.

Age is presented in years of age (centered at 83) and socio-economic status (SES) refers to social class and is coded $1=$ working class, $2=$ middle class, and $3=$ upper class, such that upper class was the reference group.

Financial satisfaction was based on the sum from three items 'How do you believe your financial situation is today as compared to other people in your age?' (worse $=1$, same $=2$ or better $=3$ ), 'How well does the money last to satisfy your needs?' (poorly $=1$, pretty poorly $=$ 2 , pretty well $=3$ or well $=4$ ) and 'Do you believe that your financial situation prevents you from doing what you want to do?' (yes $=1$, yes, to a certain extent $=2$ or no $=3$ ). The sum ranged from 3 to 10 . Cronbach's alpha at wave 1 was 0.68 .

Perceived quality of social network refers to the participant's evaluation of social contacts and was covered by four questions ('Do you have acquaintances you can talk to?', 'Do you feel you are a part of a set of friends?', 'Do you lack company?' and 'Do you feel abandoned?'). The sum ranged from 0 to 12 with high scores indicating satisfaction with the social network. Cronbach's alpha at wave 1 was 0.75 .

Self-rated overall health consisted of the following four items: 'How do you perceive your health status?' (poor $=1$, average $=2$, good $=3$ ), 'How do you perceive your current health status as compared with the status two years ago?' (worse $=1$, about same $=2$, better $=3$ ), ' How do you perceive your health status as compared to other people at your age?' (worse $=1$, about same $=2$, better $=3$ ), and 'Do you think your health status prevents you from doing things you want to do?' (yes $=1$, to an extent $=2$, not at all $=3$ ). The total sum ranged from 4 to 12 points. Cronbach's alpha at wave 1 was 0.62 .

Depression - rhe 20-item scale Center for Epidemiologic Studies Depression Scale (CES-D) was developed to assess depressive symptoms in a general population study (Radloff, 1977). On a four-point scale, participants took a position on the frequency during the last week of 20 symptoms such as; 'During the past week I felt that I could not shake off the blues even with help from my family and friends' or 'During the last week I was bothered by things that usually don't bother me.' The total sum ranged from 0 to 60 , with higher scores meaning higher frequency of depressive symptoms. The psychometric properties of the Swedish version of the scale have been examined in previous research (Gatz, Johansson, Pedersen, Berg, \& Reynolds, 1993). Cronbach's alpha at wave 1 was 0.75 .

The Locus of control scale (Rotter, 1966) was used to measure the participants' experience of being in control of their lives. Twelve questions were posed concerning perceived internal and external locus of control. Participants rated locus of control on five-point-scaled items such as: 'When I make plans, I am almost certain that I can make them work' (internal locus of control) or 'Sometimes I feel that I don't have enough control over the direction my life is taking' (external locus of control). The total sum ranged from 12 to 60, with higher scores meaning higher degree of perceived internal control. Participants returned the inventory by mail. Cronbach's alpha at wave 1 was 0.73 .

Personality variables - the 19-item Eysenck Personality Inventory, EPI, was used to measure the personality traits neuroticism and extraversion. The neuroticism scale contains questions such as: 'Are you sometimes happy, sometimes sad without any particular reason?' and the extraversion scale contains questions such as 'Do you have a lively way?' The items were dichotomous: 'yes' $=1$ and 'no' $=0$. Negative items were reverse-coded. The total sum of scores for the Extraversion scale was 0-9 with Cronbach's alpha of 0.64 at wave 1. For Neuroticism, the range was 0-10 with Cronbach's alpha of 0.75 at wave 1 . 


\section{Data analysis}

Overall trajectories and inter-individual differences in intra-individual changes in life satisfaction across a 6-year period were studied using growth curves within a mixed, or multilevel, modeling (MLM) framework using SPSS. Models differing in fixed effects were compared using maximum likelihood, and models differing in random effects only were compared using restricted maximum likelihood. The MLM analysis provides fixed effects that reflect effects of the population mean trajectory, and random effects that reflect the covariance structures of the data. Thus, fixed effects of time for life satisfaction represent polynomial changes of the population mean across the four measurement points, whereas the random effects reflect individuals' deviation from the sample mean trajectory. Furthermore, as the sample consisted of pairs of twins, both within-person and within-pair variance needed to be modeled. Because the MLM method enables the investigation of hierarchically structured data in nested models, threelevel models were applied to account for three levels of variance: within-individual (level 1), between-individual (level 2) and between-pair (level 3). Moreover, a second aim was to explore the possible influence of a set of predictors, in addition to time. Time-invariant predictors were centered such that 0 was a meaningful value to facilitate interpretation of results, whereas time-varying predictors were represented with two variables to be able to model the effects of time-level (level 1) changes and person-level (level 2) differences. The parameterization of variables is described below.

To model changes in life satisfaction across the four waves, time was centered at the first occasion, represented by two variables accounting for linear and quadratic slopes. The time-invariant predictors of age at wave 1 and gender were represented with one variable each. A 'time-in-study' metric of change was selected to represent longitudinal age-related change separately from cross-sectional age differences (which were represented by the effect of age at wave 1 ). Gender was coded with men as the reference group, and age was coded as deviation from the sample mean age at first wave (83). Each of the time-varying predictors, namely financial satisfaction, perceived quality of social network locus of control, depressive symptoms and self-rated overall health, was represented by a level 1 variable for withinperson change and a level 2 variable for between-persons differences. The within-person variables have occasion-specific values that at occasions 2, 3 and 4 reflect the deviance from the person-specific first occasion value, whereas the between-person variables have identical values across all waves that reflect the deviance at initial level from the initial sample mean (i.e. where 0 represents the sample mean). The initial sam- ple means were the following; financial satisfaction, 8.4 ( $\mathrm{SD}=1.2)$; locus of control, $37(\mathrm{SD}=4.1)$; depressive symptoms, $28.6(\mathrm{SD}=8.5)$; self-rated overall health, 9.1 $(\mathrm{SD}=1.8)$; and perceived quality of social network, 9.6 $(\mathrm{SD}=2.4)$. The time-varying variable widowhood was also represented with a within-person variable and a between-person variable. The within-person variable was permitted to vary across waves, each wave given a code for either other $=0$ or widowed $=1$; the former includes status of married, not married or divorced. The between-person variable of widowhood was given identical values across all waves for each individual, reflecting married, divorced, unmarried across all waves $=0$, widowed across all waves $=1$, or transition into widowhood $=2$, during the 6 -year period.

An unconditional means model was initially estimated to explore the partition of variability of the outcome variable Life-Satisfaction-Index-Z across the three levels of variation: within-person, between-person and between-pairs. Three unconditional growth models were then fitted to explore overall changes across time, degree of individual differences in pattern of change, and variance related to pair membership. A baseline predictor model was then estimated including age at wave 1, gender and slope interactions of age and gender as predictors of change in Life-SatisfactionIndex-Z. In a next step a series of seven models was analyzed to be able to investigate the separate contribution of the level 1 and level 2 effects of the time-varying predictors and level 2 effects of time-invariant predictors on level and changes in life satisfaction. Maximum likelihood was used to compare the model fit for each model to a baseline predictor model matched on number of cases. As the ML approach demands identical sample size in the models to be compared, the number of cases varied across the models. Table 2 presents model A: Financial satisfaction and SES; model B, Widowhood; model C, Perceived quality of social network; model D, Selfrated overall health; model E, Depressive symptoms; model F, Locus of control; and model G, Neuroticism and extraversion.

In order to identify predictors of particular relevance in a multivariate context, significant predictors that also contributed to improvements in model fit were included into the final model, presented in Table 3. The final model included only individuals with data on all predictors; therefore the sample size decreased markedly. Random effects of within-person predictor variables were also tested. A collinearity test among included variables in the final model was performed on the first measurement point data and showed a minimum tolerance value of 0.63 and a maximum VIF (Variance Inflation Factor) value of 1.59, suggesting that multicollinearity is tolerably small. 


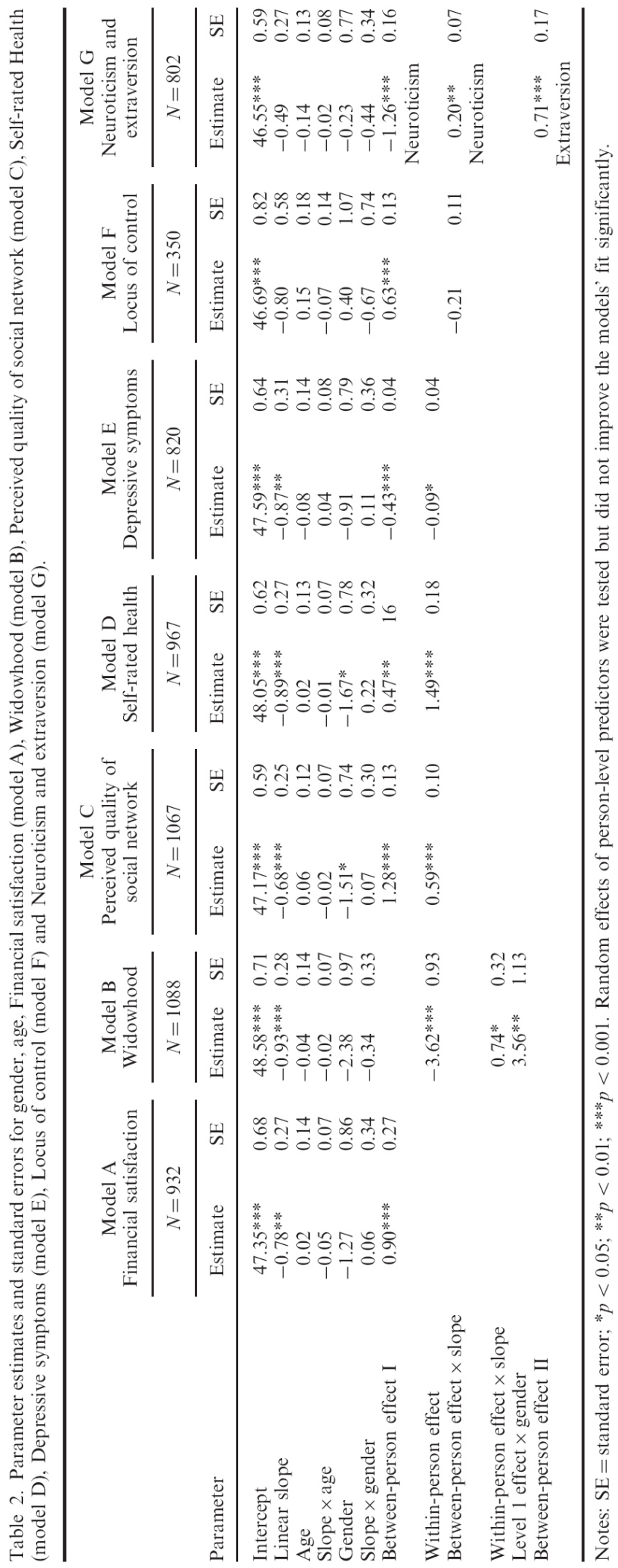


Table 3. Final model. Parameter estimates and standard errors for Financial satisfaction, Perceived quality of social network, Depressive symptoms, Locus of control, Self-rated health, Neuroticism and extraversion $(N=533)$.

\begin{tabular}{lcc}
\hline Parameter and fit statistic & Estimate & SE \\
\hline Fixed effects & & \\
$\quad$ Intercept & $46.58^{* * *}$ & 0.43 \\
Linear slope & $-0.61^{* *}$ & 0.23 \\
Financial satisfaction-BP & $0.77^{*}$ & 0.30 \\
Perceived quality of social & $0.64^{* * *}$ & 0.19 \\
$\quad$ network-BP & & \\
Perceived quality of social & $-0.34^{* * *}$ & 0.10 \\
$\quad$ network-BP $\times$ slope & $-0.17^{* *}$ & 0.06 \\
Depressive symptoms-BP & $0.33^{* * *}$ & 0.09 \\
$\quad$ Locus of control-BP & $0.67^{* *}$ & 0.22 \\
$\quad$ Self-rated health-BP & $-0.47^{*}$ & 0.19 \\
$\quad$ Neuroticism-BP & $0.59^{* *}$ & 0.19 \\
$\quad$ Extraversion-BP & 12.07 & 4.91 \\
Person-level & & \\
$\quad$ Variance of intercept & 7.54 & 4.97 \\
Twin-level & 19.30 & 1.68 \\
$\quad$ Variance of intercept &
\end{tabular}

Notes: $\mathrm{SE}=$ standard error; $\mathrm{AIC}=$ Akaikes's information criterion. ${ }^{*} p<0.05 ; * * p<0.01 ; * * * p<0.001$. Random effects of person-level predictors were tested but did not improve the model's fit significantly.

\section{Results}

Descriptive characteristics of the sample across the four measurement points are presented in Table 1. An unconditional means model was initially estimated using restricted maximum likelihood to explore the partition of variability of the outcome variable LifeSatisfaction-Index- $Z$ across the three levels of variation: within-person, between-person and betweenpairs. The variance of the intercept at the pair level accounted for $38 \%$ of the total variance, the variance of the intercept at the twin level accounted for $30 \%$, and the within-person variance across time accounted for $32 \%$. Three unconditional growth models were then fitted to explore overall changes across time, degree of individual differences in pattern of change and variance related to pair membership. The initial sample mean was 47.1 on a scale ranging from 13 to 65 , which corresponds to an average of 3.6 on a scale of 1 to 5 (i.e. between 'Neither agree nor disagree/Uncertain' and 'Slightly agree'. The fixed effects slope showed a significant decline in life satisfaction over four measurement points $(-1.49 ; \mathrm{SE}=0.43 ; p<0.001)$, but the fixed quadratic slope was not significant, although the $p$-value suggests a trend towards decelerating decline $(0.28 ; \mathrm{SE}=0.15, p=0.070)$. To investigate possible within-person and within-pair variation in rate of change in life satisfaction, the model deviance values were compared; lower deviance values indicate better fit of the model. A random linear slope at the betweenperson level showed a nonsignificant improvement of the fit statistics LR (Likelihood Ratio) $X^{2}(2)=2.7, p$ $<0.05$, indicating that a random slope for individual variance was not needed. A random linear slope at the between-pair level similarly was nonsignificant, LR $X^{2}(2)=1.37, p>0.05$, suggesting that a random slope for pair-level variance was also not needed. Thus, the magnitude of change in life satisfaction appeared relatively constant over persons and twin pairs. However, because power is often less for detecting fixed effects as compared with detecting random effects (Snijders \& Bosker, 2004), a further exploration of inter-individual differences in intra-individual change was motivated, despite nonsignificant random slope variances. Furthermore, as discussed in Raudenbush and Bryk (2002) level 1 slopes (i.e. as for the effect of time) can be characterized as fixed, random or systematically varying, where the latter category describes effects that vary systematically as a function of predictors, but do not vary randomly over persons or twin pairs. In order to evaluate this latter possibility, we examined main effects and interactions with time of our substantive predictors, as described next.

A baseline model was estimated for the demographic predictors of age and gender with slope interactions included for both. There was a significant linear decline in life satisfaction across the study $-(0.81, \mathrm{SE}=0.25, p$ $<0.001)$. The quadratic slope term was nonsignificant and therefore excluded from the model. Age and gender were not significantly related to level or change in life satisfaction, but were nevertheless included as control variables in subsequent predictor models. The estimated fit of each of the models A-G was compared to the model fit of a version of the baseline model that matched the number of cases for each model.

\section{Model A: Financial satisfaction and SES}

In the model A with best fit, presented in the second column in Table 2, greater initial financial satisfaction was significantly related to greater initial satisfaction with life $(0.90, \mathrm{SE}=0.27, p<0.001)$. The effects of changes in financial satisfaction and of SES were nonsignificant.

\section{Model B: Widowhood}

The level 1 effect of becoming widowed was significantly related to lower levels of life satisfaction in men $(-3.62, \mathrm{SE}=0.93, p<0.001)$, although this effect was significantly less negative in women (interaction $=3.56$, $\mathrm{SE}=1.13, p<0.01)$. The negative effect of being widowed on life satisfaction became less negative during the study (interaction $=0.74, \mathrm{SE}=0.32, p<0.05$ ); see column 3 in Table 2. Women had significantly lower life satisfaction before widowhood than did men $(-2.38$, SE $=0.97, p<0.05)$. The level 2 effect of widowhood was not significant. 


\section{Model C: Perceived quality of social network}

Model C is presented in the fourth column in Table 2 and shows that initial satisfaction with quality of social network was related to greater life satisfaction $(1.28$, $\mathrm{SE}=0.13, p<0.001)$ and the level 1 effect of change in social network was positively related to concurrent level of life satisfaction across the study $(0.59, \mathrm{SE}$ $=0.10, p<0.001)$. No interactions with the linear slopes were significant.

\section{Model D: Self-rated health}

Individuals who rated their initial health as better also reported greater life satisfaction $(0.47, \mathrm{SE}=0.16$, $p<0.01)$ and improved self-rated health during the study was related to concurrent greater life satisfaction $(1.49, \mathrm{SE}=0.18, p<0.001)$, see the fifth column in Table 2. The model also showed a main effect of gender on life satisfaction; women were less satisfied with their lives $(-1.67, \mathrm{SE}=0.78, p<0.05)$. No interactions with the linear slopes were significant.

\section{Model E: Depressive symptoms}

In model E presented in column 6 in Table 2, more initial depressive symptoms were related to lower initial levels of life satisfaction $(-0.43, \mathrm{SE}=0.04, p<0.001)$, and the level 1 effect of change in depressive symptoms was also negatively related to concurrent level of life satisfaction across the study $(-0.09, \mathrm{SE}=0.04, p<0.05)$. No interactions with the linear slopes were significant.

\section{Model F: Locus of control}

Column 7 in Table 2 shows that an initially more internal locus of control was significantly related to greater initial satisfaction with life $(0.63, \mathrm{SE}=0.13, p<$ 0.001). The interaction between internal locus of control and the linear slope was marginally significant $(-0.21, \mathrm{SE}=0.11, p=0.051)$, suggesting that a more internal initial locus of control was related to a steeper decline in life satisfaction across the study.

\section{Model G: Neuroticism and extraversion}

As shown in column 8 in Table 2, individuals who showed less neuroticism $(-1.26, \mathrm{SE}=0.16, \mathrm{p}<0.001)$ and more extraversion $(0.71, \mathrm{SE}=0.17, \mathrm{p}<0.001)$ reported higher initial levels of life satisfaction. Higher scores on neuroticism were also related to a less steep decline in life satisfaction across the study $(0.20, \mathrm{SE}=$ $0.07, \mathrm{p}<0.01)$. The interaction between the linear slope and extraversion was nonsignificant.

\section{Final model}

Table 3 presents the final model that includes only the predictors that significantly improved the model fit from models A-G. There was a significant decline in life satisfaction over time, as evaluated for someone of average initial levels of social network $(-0.61, \mathrm{SE}=0.23$, $p<0.01)$. Higher initial levels of financial satisfaction were significantly related to higher levels of life satisfaction $(0.77, \mathrm{SE}=0.30, p<0.05)$. Greater initial quality of social network was significantly related to greater initial satisfaction with life $(0.64, \mathrm{SE}=0.19, p<0.001)$ and a steeper decline in life satisfaction across the study $(-0.34, \mathrm{SE}=0.10, p<0.001)$. Greater initial depressive symptoms were related to lower levels of life satisfaction $(-0.17, \mathrm{SE}=0.06, p<0.01)$. Better self-rated initial health $(0.67, \mathrm{SE}=0.22, p<0.01)$ and a more internal locus of control $(0.33, \mathrm{SE}=0.09, p<0.001)$ were significantly related to greater life satisfaction. Finally, individuals with lower levels of neuroticism $(-0.47, \mathrm{SE}=0.19$, $p<0.05)$ and higher levels of extraversion $(0.59, \mathrm{SE}=$ $0.19, p<0.01)$ reported higher levels of life satisfaction.

\section{Discussion}

The aim of the study was to investigate the overall pattern of change in life satisfaction over 6 years in individuals aged 80 years and older, as well as prediction of inter-individual differences in intra-individual changes in life satisfaction. The majority of the predictors examined were those previously found to be significant markers of life satisfaction at first measurement occasion in the same sample (Berg et al., 2006). However, financial satisfaction and the personality traits of neuroticism and extraversion were added so as to expand our understanding of life satisfaction within a wider range of relevant associates. In order to investigate what matters for life satisfaction in the absence of competing predictors, the predictors were first examined in separate models (models A-G). To be able to identify the predictors that mattered most, a final model was estimated including the significant predictors that each contributed to an improved model fit in the separate models.

The present study shows that overall level of life satisfaction decreased with a largely similar magnitude across individuals over a 6-year period. Mroczek and Spiro (2005) also found a decline in life satisfaction in very old age, but individuals varied in amount of change. One explanation as to the difference in results might be different ages of the samples. Whereas Mroczek and Spiro's study measured life satisfaction from adulthood to the maximum age of 85 with a mean age of 40 years at entry, our sample was aged 80 years and over with a mean age of 83 years at entry. Given that there is a distinct increase in morbidity and psychosocial losses with advanced age, life satisfaction may possibly decrease in a more homogeneous way in the age group of 80 and over. Moreover, the use of different time structures to measure the change in life satisfaction in the studies may explain the inconsistent results. The use of an age-based time structure does 
not separate cross-sectional (cohort) and longitudinal (age) effects, whereas a time-in-study time structure, as used in the current study, does permit separate estimation of these effects.

Below the predictors of significance for level or change in life satisfaction as identified in models A-G will be discussed, also taking into consideration the results from the final model that investigated predictors of specific relevance for life satisfaction in the presence of all significant predictors (from models A-G).

Changes in marital status related to widowhood were found to relate to life satisfaction and, in line with previous research, men were particularly afflicted by the loss of their spouse (Cheng \& Chan, 2006; Chipperfield \& Havens, 2001). The gender difference possibly reflects different marital roles in the cohort born in the first part of the twentieth century. First, marriage provides different psychosocial gains in men and women; men have fewer friends and their wife may be the only close confidant (Chappell, 1989; Strain \& Chappell, 1982). Secondly, as men in this cohort are less accustomed than women to taking care of domestic chores, widowhood brings additional practical difficulties and disability to the psychosocial loss. Thus, the explanations of the findings suggest that the difference will be less distinct in younger cohorts. The effect of widowhood was not significant in the context of other predictors in the final model.

Financial satisfaction and life satisfaction were significantly related on a cross-sectional level and the relationship was significant even in the context of other predictors. Objective measures of income and wellbeing were found to be relatively weak in Pinquart and Sorensen's meta-analysis (Pinquart \& Sorensen, 2000), and the explanation of the results was that the elderly adjust their needs and desires to reduced income and thereby keep the level of well-being unaffected. However, the use of income as a one-dimensional measure of financial situation may be inadequate. To form an accurate representation of the financial situation, the measure of income should be modified in relation to household costs (Hsieh, 2003). Thus, conclusions of a weak relationship between financial situation and well-being should be drawn with caution. In another study, economic deprivation was found to be related to life satisfaction (Revicki \& Mitchell, 1990), and along with our findings of the relevance of satisfaction with income, the finding suggests that financial security may be a vital to life satisfaction in old age.

In our previous cross-sectional study, the quality of social network was the most powerful marker of life satisfaction (Berg et al., 2006). In the present study, greater levels of initial satisfaction with social network were related to greater initial levels of life satisfaction but steeper rates of decline. However, in model C, indi- viduals who became more satisfied with their social network also became more satisfied with life, suggesting a close relationship between quality of life and life satisfaction. Findings of increased dependency as a result of aging-related diseases and disability might explain why life satisfaction and quality of social network are closely related in late life (Newsom \& Schulz, 1996; Pinquart \& Sorensen, 2000). Being satisfied with one's social contacts may buffer the dissatisfaction due to the reduced functional capacity. Carstensen's theory of socio-emotional selectivity offers an alternative explanation to the close relationship between life satisfaction and quality of social network (Carstensen, 1992). As people age and future time perception changes, they tend to select fewer but more emotionally rewarding contacts at the expense of investing their time in maintaining a large network. The links between quality of social network and life satisfaction in old age probably involves multiple and interrelating factors. The finding that people who initially were more satisfied with their social network showed a greater decline in life satisfaction across the study in the final model most possibly reflects floor effects: individuals who initially were low on the LSI-Z had a more limited scope of possible decline as compared with whose were high in LSI-Z.

Fewer depressive symptoms at first wave were related to higher levels of life satisfaction in both model $\mathrm{D}$ and in the final model in our study, a finding in correspondence with previous studies (Demura \& Sato, 2003; Fiske et al., 2003). The longitudinal relationship found in model D that increases in depressive symptoms were related to lower satisfaction with life across the study emphasizes efforts to improve identification and treatment of depression. Including depressive symptoms as a predictor in the study of life satisfaction may be problematic, however, as they both constitute elements of the well-being concept. In the present study life satisfaction and depressive symptoms at first wave correlated significantly $(r=-0.427, N=438$, $p<0.01)$, but the shared variance $(18 \%)$ suggests that they are largely separate constructs.

Individuals with more internal locus of control were more satisfied with their lives on a cross-sectional level, a finding in agreement with previous findings of locus of control as a stable associate of life satisfaction in late life (Hickson et al., 1988; Landau \& Litwin, 2001). However, our finding questions the possibility of locus of control as a longitudinal predictor of life satisfaction.

The finding that both higher levels on extraversion and lower levels of neuroticism were related to higher levels of life satisfaction is in line with previous research (Costa \& McCrae, 1980; Headey \& Wearing, 1989; Hilleras et al., 1999, 2001). Also, in model 
$\mathrm{G}$, higher levels of neuroticism were related to a less steep decline in life satisfaction; individuals who were high in neuroticism were less satisfied with life at first measurement but decreased less in life satisfaction across the study. The finding is also possibly a methodological artifact in terms of a floor effect: individuals already low in life satisfaction have less room for a decline over time.

A limitation of the present study is the selected sample, which due to attrition related to the data collection procedure of the LSI-Z, restricts the generalization of our findings to generally healthier and higher-functioning individuals. On the other hand, the use of selfreporting inventories presupposes a basic level of cognitive functioning in the respondent; thus, there is an implicit selectivity attached to the use of such instruments. Furthermore, due to high mortality rates at these ages, the sample size decreased drastically across the waves. However, the use of maximum likelihood permits unbiased inferences under the assumption of missing at random, which is probably more reasonable than listwise deletion, which requires missing completely at random.

One of the strengths of the present study is the longitudinal design of life satisfaction in the oldest-old and the inclusion of predictors previously identified as correlates in a cross-sectional design. Cross-sectional studies are suitable for reflecting correlates of life satisfaction in a certain cohort, but only longitudinal studies can answer questions of long-term associations both between and within persons. In the present study, associations of life satisfaction with depressive symptoms, perceived quality of social network and widowhood were found within-persons, but not betweenpersons, and thus such findings would probably have not been observed within cross-sectional studies. Also, by initially estimating effects of a wide range of relevant predictors on life satisfaction separately and then in an extended model exploring the most powerful predictors simultaneously, we were able to identify predictors of unique importance. Taken together, the study provides novel information within a largely unexplored area of research.

Although the present study showed an overall decrease in life satisfaction, certain markers predicted change in life satisfaction. The loss of spouse was related to a drop in life satisfaction, in particular in men, and reporting fewer depressive symptoms across the study was associated with higher levels of life satisfaction. The findings presented in the study exemplify that associates of relevance for life satisfaction at one time point veil complex associations that need to be examined within a longitudinal design. In order to identify predictors that mattered most, we included a range of competing predictors of isolated importance and we found mainly a set of predictors that accounted for cross-sectional variability but that were not related to changes in life satisfaction over time.

\section{Acknowledgements}

This study was supported by National Institutes of Health, NIA (AG 08861), and the Swedish Council for Working Life and Social Research, FAS (2002-0659).

\section{References}

Barer, B.M. (1994). Men and women aging differently. International Journal of Aging and Human Development, 38(1), 29-40.

Berg, A.I., Hassing, L.B., McClearn, G.E., \& Johansson, B. (2006). What matters for life satisfaction in the oldest-old? Aging and Mental Health, 10(3), 257-264.

Bowling, A. (1990). Associations with life satisfaction among very elderly people living in a deprived part of inner London. Social Science \& Medicine, 31(9), 1,003-1,011.

Bowling, A., Farquhar, M., \& Grundy, E. (1996). Associations with changes in life satisfaction among three samples of elderly people living at home. Journal of Geriatric Psychiatry, 11, 127-132.

Carstensen, L.L. (1992). Motivation for social contact across the life span: A theory of socioemotional selectivity. Nebraska Symposium on Motivation, 40, 209-254. Chamberlain, K.Z.S. (1988). Religiosity, life meaning and wellbeing: Some relationships in a sample of women. Journal for the Scientific Study of Religion, 27(3), 411-420.

Chappell, N.L. (1989). Health and helping among the elderly. Journal of Aging and Health, 1, 102-120.

Cheng, S.T., \& Chan, A.C. (2006). Relationship with others and life satisfaction in later life: Do gender and widowhood make a difference? Journals of Gerontology Series B: Psychological Sciences and Social Sciences, 61(1), P46-53.

Chipperfield, J.G., \& Havens, B. (2001). Gender differences in the relationship between marital status transitions and life satisfaction in later life. Journals of Gerontology Series B: Psychological Sciences and Social Sciences, 56(3), P176-186.

Chou, K.-L., \& Chi, I. (1999). Determinants of life satisfaction in Hong Kong Chinese elderly: A longitudinal study. Aging and Mental Health, 3(4), 328-335.

Costa Jr, P.T., \& McCrae, R.R. (1980). Influence of extraversion and neuroticism on subjective well-being: Happy and unhappy people. Journal of Personality and Social Psychology, 38(4), 668-678.

Demura, S., \& Sato, S. (2003). Relationships between depression, lifestyle and quality of life in the community dwelling elderly: A comparison between gender and age groups. Journal of Physiological and Anthropology and Applied Human Science, 22(3), 159-166.

Dent, O.F., Waite, L.M., Bennett, H.P., Casey, B.J., Grayson, D.A., Cullen, J.S., et al. (1999). A longitudinal study of chronic disease and depressive symptoms in a community sample of older people. Aging and Mental Health, 3(4), 351-357.

Diener, E. (1984). Subjective well-being. Psychological Bulletin, 95(3), 542-575.Diener, E., Suh, E.M., Lucas, R.E., \& Smith, H.L. (1999). Subjective well-being: Three decades of progress. Psychological Bulletin, 125(2), 276-302.

Fiske, A., Gatz, M., \& Pedersen, N.L. (2003). Depressive symptoms and aging: The effects of illness and non- 
healthrelated events. Journals of Gerontology Series B: Psychological Sciences and Social Sciences, 58(6), P320-328.

Gatz, M., Johansson, B., Pedersen, N., Berg, S., \& Reynolds, C. (1993). A cross-national self-report measure of depressive symptomatology. International Psychogeriatrics/IPA, 5(2), 147-156.

George, L.K., Okun, M.A., \& Landerman, R. (1985). Age as a moderator of the determinants of life satisfaction. Research on Aging, 7(2), 209-233.

Haynie, D.A., Berg, S., Johansson, B., Gatz, M., \& Zarit, S.H. (2001). Symptoms of depression in the oldest old: A longitudinal study. Journals of Gerontology Series B: Psychological Sciences and Social Sciences, 56(2), P111-118.

Headey, B., \& Wearing, A. (1989). Personality, Life Events, and Subjective Well-Being: Toward a Dynamic Equilibrium Model. United States: American Psychological Association.

Hickson, J., Housley, W.F., \& Boyle, C. (1988). The relationship of locus of control, age, and sex to life satisfaction and death anxiety in older persons. International Journal of Aging and Human Development, 26(3), 191-199.

Hilleras, P.K., Jorm, A.F., Herlitz, A., \& Winblad, B. (1999). Activity patterns in very old people: a survey of cognitively intact subjects aged 90 years or older. Age and Ageing, 28(2), 147-152.

Hilleras, P.K., Jorm, A.F., Herlitz, A., \& Winblad, B. (2001). Life satisfaction among the very old: A survey on a cognitively intact sample aged 90 years or above. International Journal of Aging and Human Development, 52(1), 71-90.

Hsieh, C.M. (2003). Income, age and financial satisfaction. International Journal of Aging and Human Development, 56(2), 89-112.

Kessler, R.C., Foster, C., Webster, P.S., \& House, J.S. (1992). The relationship between age and depressive symptoms in two national surveys. Psychology and Aging, 7(1), 119-126.

Landau, R., \& Litwin, H. (2001). Subjective well-being among the old-old: The role of health, personality and social support. International Journal of Aging and Human Development, 52(4), 265-280.

Lucas, R.E., Clark, A.E., Georgellis, Y., \& Diener, E. (2003). Reexamining adaptation and the set point model of happiness: Reactions to changes in marital status. Journal of Personality and Social Psychology, 84(3), 527-539.

Lucas, R.E., Diener, E., \& Suh, E. (1996). Discriminant validity of well-being measures. Journal of Personality and Social Psychology, 71(3), 616-628.

McCamish-Svensson, C., Samuelsson, G., Hagberg, B., Svensson, T., \& Dehlin, O. (1999). Social relationships and health as predictors of life satisfaction in advanced old age: Results from a Swedish longitudinal study. International Journal of Aging and Human Development, 48(4), 301-324.

McClearn, G.E., Johansson, B., Berg, S., Pedersen, N.L., Ahern, F., Petrill, S.A., et al. (1997). Substantial genetic influence on cognitive abilities in twins 80 or more years old. Science, 276(5318), 1,560-1,563.

Mroczek, D.K., \& Spiro 3rd, A. (2005). Change in life satisfaction during adulthood: Findings from the veterans affairs normative aging study. Journal of Personality and Social Psychology, 88(1), 189-202.

Myers, D.G., \& Diener, E. (1995). Who is happy? Psychological Science, 6(1), 10-19.

Nagata, A., Yamagata, Z., Nakamura, K., Miyamura, T., \&
Asaka, A. (1999). Sex differences in subjective well-being and related factors in elderly people in the community aged 75 and over. Nippon Ronen Igakkai Zasshi, 36(12), 868-873.

Neugarten, B.L., Havighurst, R.J., \& Tobin, S.S. (1961). The measurement of life satisfaction. Journals of Gerontology, 16, 134-143.

Newsom, J.T., \& Schulz, R. (1996). Social support as a mediator in the relation between functional status and quality of life in older adults. Psychology and Aging, 11(1), 34-44.

Padoani, W., Dello-Buono, M., Marietta, P., Scocco, P., Zaghi, P.C., \& De-Leo, D. (1998). Cognitive performance and quality of life in a sample of 220 nondemented elderly people. Archives of Gerontology and Geriatrics, Suppl 6, 373-380.

Pinquart, M., \& Sorensen, S. (2000). Influences of socioeconomic status, social network, and competence on subjective well-being in later life: A meta-analysis. Psychology and Aging, 15(2), 187-224.

Pinquart, M., \& Sorensen, S. (2001). Gender differences in self-concept and psychological well-being in old age: A meta-analysis. Journals of Gerontology Series B: Psychological Sciences and Social Sciences, 56(4), P195-213.

Radloff, L.S. (1977). The CES-D scale: A self-report depression scale for research in the general population. Applied Psychological Measurement, 1, 385-401.

Raudenbush, S.W., \& Bryk, A.S. (2002). Hierarchical Linear Models: Applications and Data Analysis Methods. London: Sage Publications.

Revicki, D.A., \& Mitchell, J.P. (1990). Strain, social support, and mental health in rural elderly individuals. Journal of Gerontology, 45(6), S267-274.

Roberts, R.E., Kaplan, G.A., Shema, S.J., \& Strawbridge, W.J. (1997). Prevalence and correlates of depression in an aging cohort: The Alameda County Study. Journals of Gerontology Series B: Psychological Sciences and Social Sciences, 52(5), S252-258.

Rotter, J.B. (1966). Generalized expectancies for internal versus external control of reinforcement. Psychological Monographs, 80(1), 1-28.

Simmons, S.F., Johansson, B., Zarit, S.H., Ljungquist, B., Plomin, R., \& McClearn, G.E. (1997). Selection bias in samples of older twins? A comparison between octogenarian twins and singletons in Sweden. Journal of Aging and Health, 9(4), 553-567.

Snijders, T.A.B., \& Bosker, R.J. (2004). Multilevel Analysis: An Introduction to Basic and Advanced Multilevel Modeling. London: Sage Publications.

Strain, L.A., \& Chappell, N.L. (1982). Confidants: Do they make a difference in quality of life? Research on Aging, 4, 479-502.

Wallace, J., \& O'Hara, M.W. (1992). Increases in depressive symptomatology in the rural elderly: Results from a cross-sectional and longitudinal study. Journal of Abnormal Psychology, 101(3), 398-404.

Wolinsky, F.D., Wyrwich, K.W., Babu, A.N., Kroenke, K., \& Tierney, W.M. (2003). Age, aging, and the sense of control among older adults: A longitudinal reconsideration. Journals of Gerontology: Series B: Psychological Sciences and Social Sciences, 58B(4), S212-S220.

Wood, V., Wylie, M.L., \& Sheafor, B. (1969). An analysis of a short self-report measure of life satisfaction: Correlation with raterjudgments. Journals of Gerontology, 24(4), 465-469. 